\title{
Photocatalytic activity of biogenic silver nanoparticles synthesized using yeast (Saccharomyces cerevisiae) extract
}

\author{
Kaushik Roy • C. K. Sarkar • C. K. Ghosh
}

Received: 23 November 2014/Accepted: 17 December 2014/Published online: 31 December 2014

(C) The Author(s) 2014. This article is published with open access at Springerlink.com

\begin{abstract}
Synthesis of metallic and semiconductor nanoparticles through physical and chemical route is quiet common but biological synthesis procedures are gaining momentum due to their simplicity, cost-effectivity and ecofriendliness. Here, we report green synthesis of silver nanoparticles from aqueous solution of silver salts using yeast (Saccharomyces cerevisiae) extract. The nanoparticles formation was gradually investigated by UV-Vis spectrometer. X-ray diffraction analysis was done to identify different phases of biosynthesized Ag nanoparticles. Transmission electron microscopy was performed to study the particle size and morphology of silver nanoparticles. Fourier transform infrared spectroscopy of the nanoparticles was performed to study the role of biomolecules capped on the surface of Ag nanoparticles during interaction. Photocatalytic activity of these biosynthesized nanoparticles was studied using an organic dye, methylene blue under solar irradiation and these nanoparticles showed efficacy in degrading the dye within a few hours of exposure.
\end{abstract}

Keywords Biogenic silver nanoparticles .

Yeast (Saccharomyces cerevisiae) extract .

UV-Vis spectroscopy $\cdot$ XRD · TEM ·

Photocatalytic activity

\footnotetext{
K. Roy · C. K. Sarkar

Department of Electronics and Telecommunication Engineering, Jadavpur University, Kolkata 700032, India

K. Roy $(\bowtie) \cdot$ C. K. Ghosh

School of Material Science and Nanotechnology, Jadavpur

University, Kolkata 700032, India

e-mail: lordkaushikroy@gmail.com
}

\section{Introduction}

Synthesis of metallic and semiconductor nanoparticles through various routes is a primary step for nano-research. The size, shape and morphology of the nanoparticles can be varied and modified to obtain enhanced property for suitable applications ( $\mathrm{Li}$ et al. 2011a, b). The nano-sized particles possess large number of surface atoms that contribute to large surface area. Due to high surface area, these particles exhibit improved electronic (Löberg et al. 2013; Zaniewski et al. 2013), optical (Kelly et al. 2003) and catalytic (Bastús et al. 2014) properties than bulk materials. The noble metallic nanoparticles may be incorporated for numerous applications in different fields like electronics (Tran et al. 2013), microscopy (Lee and El-Sayed 2006), biomedicines (Huang et al. 2011; Satyavani et al. 2011) and textile (Zhang et al. 2009). In textile and paper industry, recently silver nanoparticles are used to degrade the organic dyes as they exhibit enhanced photocatalytic property for degrading organic dyes under solar radiation (Kumar et al. 2013). Recent reports suggest that the removal of organic dyes using Ag nanoparticles is a better choice than the common dye removal techniques like redox treatment (Kim and Hensley 1997), electro-coagulation (Szpyrkowicz 2005), carbon sorption (Gomez et al. 2007) and UV photodegradation (Comparelli et al. 2005; Sohrabi and Ghavami 2008).

In this paper, we studied the photocatalytic degradation of methylene blue dye in presence of biogenic silver nanoparticles synthesized using yeast (Saccharomyces cerevisiae) extract. The biological route was chosen over common chemical and physical procedures because it is an easy, fast and eco-friendly option and does not involve any costly instrument or hazardous by-product as well (Awwad et al. 2013). In recent times, plant-mediated (Banerjee et al. 
2014; Roy et al. 2013; Phanjom et al. 2012) and microbemediated (Sudha et al. 2013; Malarkodi et al. 2013; Honary et al. 2013) synthesis procedures are frequently used for nanoparticle synthesis. But in particular, the microbemediated synthesis methods involve various isolation and culture techniques which are multi-step complicated procedures and time-consuming ( $\mathrm{Li}$ et al. 2012; Bonde et al. 2012). For biosynthesis of Ag nanoparticles, we used the powder of yeast (Saccharomyces cerevisiae) extract which is readily available in market and contains the bioactive molecules that are able to reduce silver ions and stabilize the colloidal particles in the medium (Mosser et al. 2011; Li et al. 2011a, b). Here, we have successfully synthesized silver nanoparticles from $\mathrm{AgNO}_{3}$ solution using yeast (Saccharomyces cerevisiae) extract and these nanoparticles have shown the efficiency in degrading methylene blue under solar irradiation.

\section{Materials and methods}

\section{Materials}

Extract powder of yeast (Saccharomyces cerevisiae) was purchased from Merck Specialties Pvt. Ltd. India. Pure silver nitrate $\left(\mathrm{AgNO}_{3}\right)$ and methylene blue (powder) used here were the products of Merck India Ltd.

\section{Methods}

\section{Synthesis of silver nanoparticles}

To prepare yeast (Saccharomyces cerevisiae) extract solution of $1 \mathrm{~g} / \mathrm{l}$ concentration, $0.1 \mathrm{~g}$ dry powder of the extract was dissolved in $100 \mathrm{ml}$ de-ionized (DI) water. $0.34 \mathrm{~g}$ silver nitrate was dissolved in $100 \mathrm{ml} \mathrm{DI}$ water to prepare $20 \mathrm{mM}$ stock solution of $\mathrm{AgNO}_{3}$ for further use. To prepare silver nanoparticles, the silver ions present in the $\mathrm{AgNO}_{3}$ solution was reduced using solution of yeast (Saccharomyces cerevisiae) extract. The $100 \mathrm{ml}$ solution of yeast extract was added dropwise to the $100 \mathrm{ml}$ aqueous solution of $\mathrm{AgNO}_{3}$ resulting into a half diluted mixture $(10 \mathrm{mM})$ of silver nitrate with exposure to the fungal extract. Formation of silver nanoparticles at room temperature was visually detected by gradual change in the color of the mixture (shown in Fig. 1) and later investigated by UV-Vis spectroscopy. When reaction completed (after $24 \mathrm{~h}$ of observation), the mixture was centrifuged at $10,000 \mathrm{rpm}$ for $30 \mathrm{~min}$ to separate colloidal particles from the mixture. After centrifugation, the supernatant was decanted and the obtained precipitation was dissolved in $20 \mathrm{ml}$ DI water for further centrifugation at 5,000 rpm for $10 \mathrm{~min}$. In this way, maximum biomass residue was

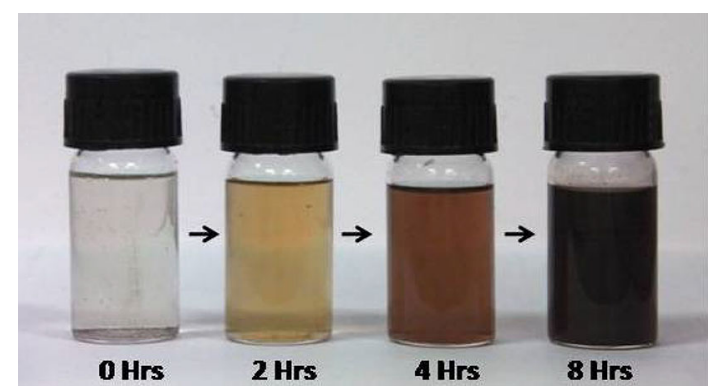

Fig. 1 Color change with reaction time

removed from the surface of nanoparticles and the level of purity of these silver nanoparticles was enhanced. At last, the pellet of nanoparticles formed at the bottom of centrifuge tube was collected and dried inside a vacuum dryer to obtain dry powder of biosynthesized $\mathrm{Ag}$ nanoparticles.

\section{Characterization of silver nanoparticles}

The formation of silver nanoparticles in the mixture was studied by measuring the absorption spectra of the mixture at regular interval using Perkin Elmer UV-Vis spectrometer (USA). The XRD analysis of dry silver nanoparticles was performed by Rigaku Ultima-III X-ray diffractometer $(\lambda=0.154$; operating voltage $40 \mathrm{kV})$. FTIR study of these biosynthesized nanoparticles was carried out using IRPrestige FTIR spectroscope (Shimadzu). To prepare sample grid for TEM analysis, the dry powder of silver nanoparticles was suspended in small amount of DI water keeping a concentration of $50 \mu \mathrm{g} / \mathrm{ml}$. A drop of this suspension was placed on carbon-coated copper grid and the grid was dried before scanning under high-resolution JEOL-2010 TEM (operating voltage $200 \mathrm{kV}$ ).

\section{Study of photocatalytic activity of Ag nanoparticles}

The photocatalytic activity of these biosynthesized $\mathrm{Ag}$ nanoparticles was studied by degradation of methylene blue under sunlight irradiation. Initially, the dye solution was prepared by dissolving $1 \mathrm{mg}$ powder of methylene blue in $100 \mathrm{ml}$ DI water (keeping $10 \mathrm{mg} / \mathrm{l}$ concentration). Around $10 \mathrm{mg}$ of silver nanoparticles was added to $50 \mathrm{ml}$ dye solution of methylene blue and the mixture was stirred magnetically for $45 \mathrm{~min}$ in darkness before exposing to sunlight. A control was prepared and kept under the similar condition for comparing any change in color of the dye solution. The colloidal suspension was then put under sunlight irradiation with constant stirring. The average temperature of the ambience during the experiment was found to be around $27{ }^{\circ} \mathrm{C}$ with $6 \mathrm{~h}$ mean shine duration (Kolkata: $22^{\circ} 32^{\prime} \mathrm{N}, 88^{\circ} 19^{\prime} \mathrm{E}$; Date: 12th June, 2014). At frequent intervals (every $2 \mathrm{~h}$ ), $2 \mathrm{ml}$ suspension was taken 
from the colloidal mixture and centrifuged at 5,000 rpm for 15 min to obtain clean supernatant soup of the tested dye. The soup was then scanned at different wavelength from 350 to $850 \mathrm{~nm}$ using the Perkin Elmer UV-Vis spectroscope (USA) to study the dye degradation in presence of Ag nanoparticles.

\section{Result and discussions}

\section{$\mathrm{UV}-\mathrm{V}$ is spectroscopy}

As the yeast extract powder is a rich source of functional organic molecules, it has the ability to reduce silver cations in the reacting solution. After a few hours of addition of yeast extract to the $\mathrm{AgNO}_{3}$ solution, the color of the solution began to change from colorless to yellow indicating the formation of $\mathrm{Ag}$ nanoparticles in the mixture. The color of the solution gradually intensified with incubation time and turned into dark brown after $4 \mathrm{~h}$ as shown in Fig. 1. This change of solution color may be attributed to the surface plasmon resonance of $\mathrm{Ag}$ nanoparticles (Prakasha et al. 2013). The production of nanoparticles was monitored by scanning the mixture using a UV-Vis spectrometer at regular interval. The maximum absorbance noticed at $450 \mathrm{~nm}$ further confirmed the formation of nanoparticles in the mixture. The UV-Vis spectra obtained at different time intervals $(2,4,8$ and $16 \mathrm{~h}$ ) are shown in Fig. 2. The maximum absorbance was found to be increasing with incubation time and its variation with time is shown in Fig. 2 (inset). It is clear from the inset figure that the absorbance continued to increase almost linearly up to $8 \mathrm{~h}$ of incubation perhaps due to formation of more number of nanoparticles in the reacting mixture. After $16 \mathrm{~h}$

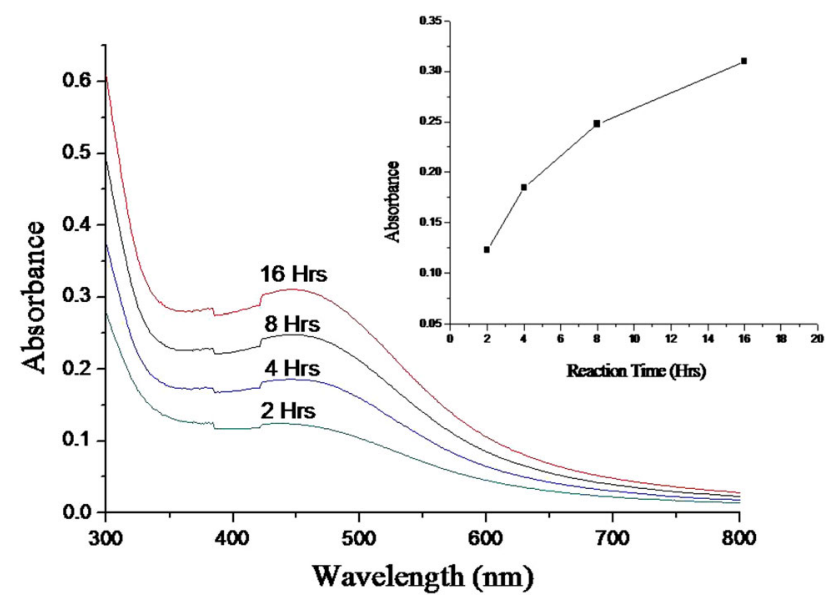

Fig. 2 UV spectra of the reacting mixture at different time intervals. Inset curve indicates the variance of maximum absorbance with incubation time of incubation, the formation rate saturated indicating the completion of reaction.

XRD analysis

Crystallinity and different phases of biogenic nanoparticles were identified by analyzing X-ray diffraction pattern. The XRD pattern (shown in Fig. 3) consists of six noticeable peaks at $2 \theta=27.62^{\circ}, 32.04^{\circ}, 46.1^{\circ}, 54.74^{\circ}, 57.38^{\circ}$ and $76.82^{\circ}$ which, respectively, correspond to (220), (122), (231), (331), (241) and (311) planes of Ag (as correlated to JCPDS: File No. 4-783). This result shows that these nanoparticles are crystalline and face-centered cubic in nature.

\section{TEM analysis}

The size, shape and morphology of the biogenic silver nanoparticles were studied by transmission electron microscopy (TEM). The high-resolution TEM images (Fig. 4) show that the particles are almost spherical in shape with an average diameter of $10 \mathrm{~nm}$. The lattice fringes denote high crystallinity with an interplanar spacing of $0.28 \mathrm{~nm}$ that can be attributed to the (122) planes of FCC phase of biosynthesized silver nanoparticles.

\section{FTIR spectroscopy}

Figure 5 shows the FTIR spectrum of the silver nanoparticles synthesized using yeast (Saccharomyces cerevisiae) extract. This characterization was done to detect the functional organic molecules which cause the production and capping of biogenic Ag nanoparticles in the mixture. The spectrum (in absorbance mode) consists of six

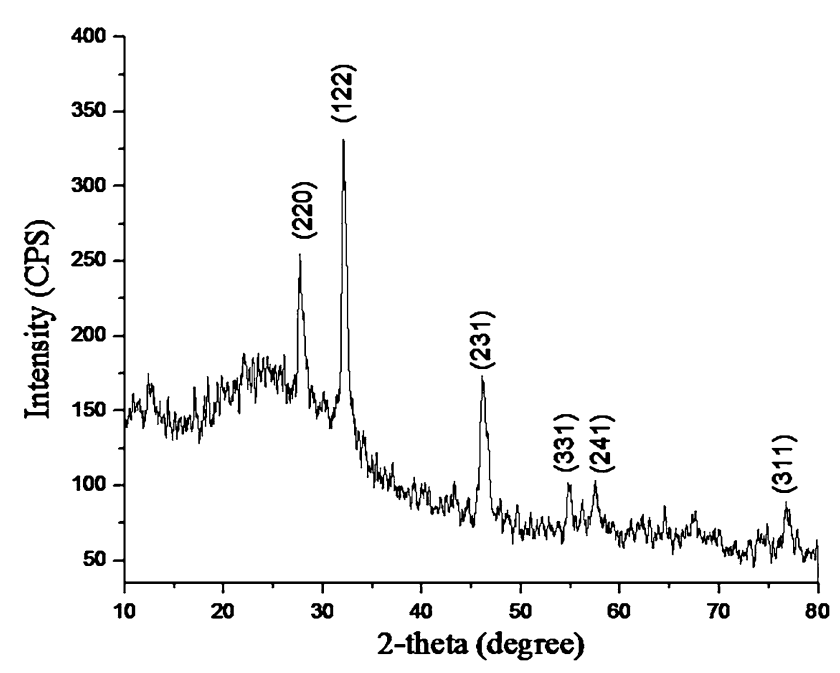

Fig. 3 X-ray diffraction curve of biosynthesized Ag nanoparticles

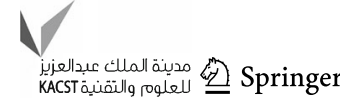


Fig. 4 TEM images of biogenic silver nanoparticles
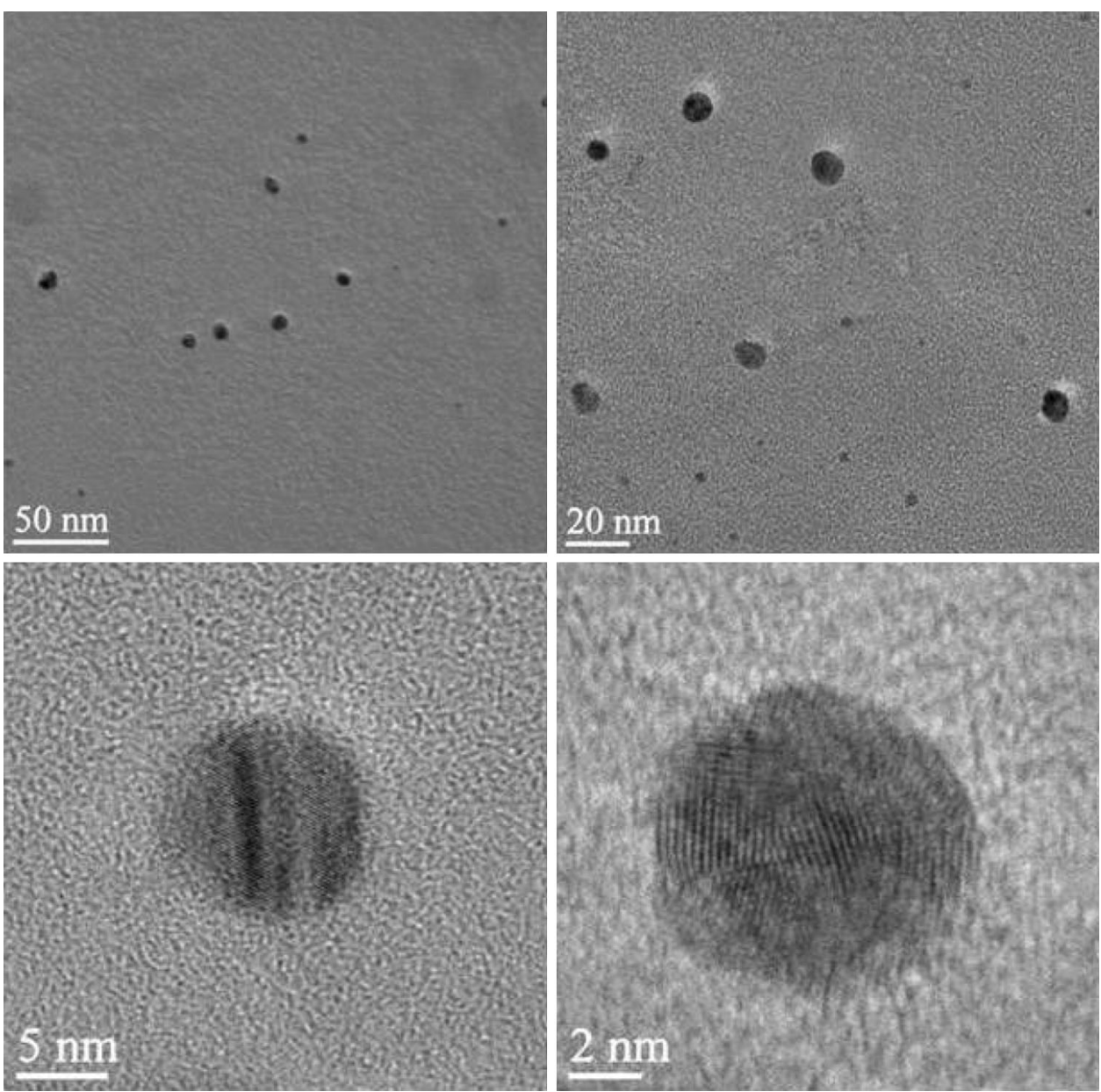

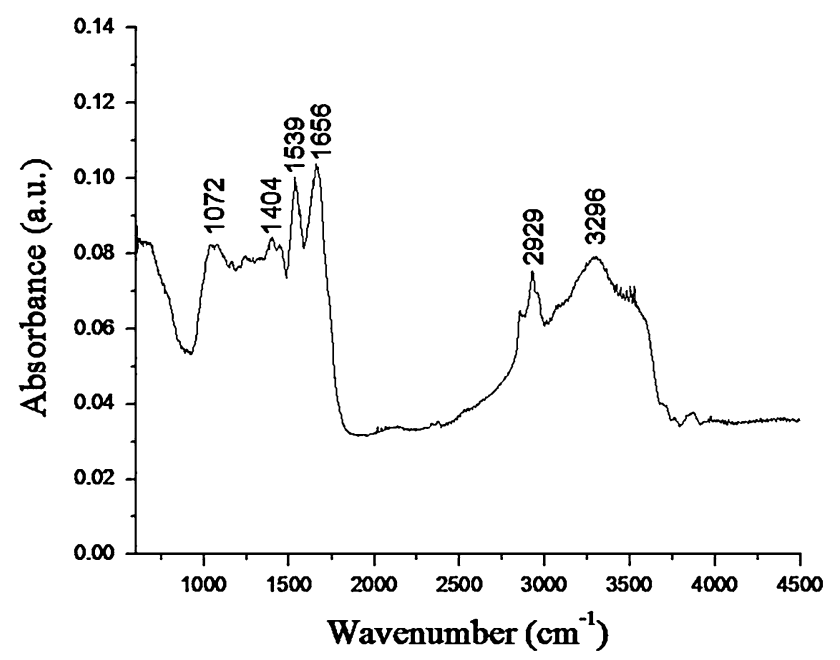

Fig. 5 FTIR spectrum of the biosynthesized silver nanoparticles

noticeable peaks between 500 and $4,500 \mathrm{~cm}^{-1}$. Bands noticed at 1,656 and $1,404 \mathrm{~cm}^{-1}$ may be assigned to the $\mathrm{C}=\mathrm{O}$ stretching vibration of amides and $\mathrm{C}-\mathrm{H}$ bending of alkanes, respectively (Smith 1999). A band at $1,072 \mathrm{~cm}^{-1}$ may indicate stretching of $\mathrm{C}-\mathrm{N}$ bonds that exist in amines whereas the band at $3,296 \mathrm{~cm}^{-1}$ denotes the $\mathrm{O}-\mathrm{H}$ stretching of aromatic compounds like phenol. (Isaac et al. 2013). The band observed at $2,929 \mathrm{~cm}^{-1}$ may correspond to the $\mathrm{C}-\mathrm{H}$ stretching of aldehydes and a band at $1,539 \mathrm{~cm}^{-1}$ indicates the bending of $\mathrm{C}-\mathrm{H}$ bonds present in hydrocarbons as well (Sathyavathi et al. 2010). From this study, it is clear that the functional molecules like aldehydes, amides and phenols present in yeast extract could possibly reduce the $\mathrm{Ag}^{+}$ions and stabilize the biosynthesized nanoparticles in the mixture.

\section{Analysis of photocatalytic activity}

Photocatalytic activity of the biosynthesized silver nanoparticles was evaluated by degradation of methylene blue under solar irradiation. Dye degradation was visually detected by gradual change in the color of the dye solution from deep blue to colorless (shown in Fig. 6). The characteristic absorption peak for methylene blue was noticed at $660 \mathrm{~nm}$. The degradation of the dye in presence of biogenic Ag nanoparticles was verified by the decrease of the peak intensity (at $660 \mathrm{~nm}$ ) during $6 \mathrm{~h}$ of exposure in sunlight (shown in Fig. 7). 
Fig. 6 Gradual change in dye color from blue to colorless denotes dye degradation
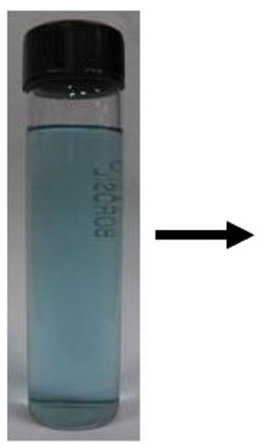

Initial

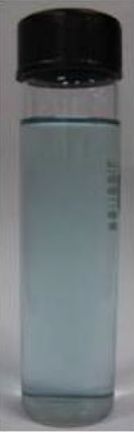

$1 \mathrm{hr}$

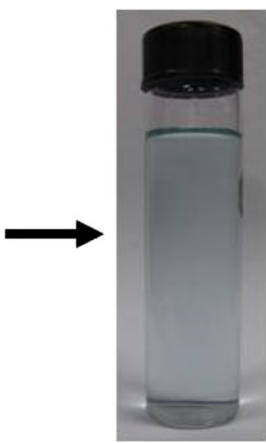

$2 \mathrm{hrs}$

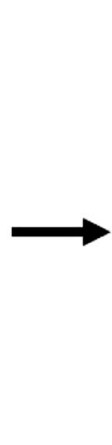

4 hrs

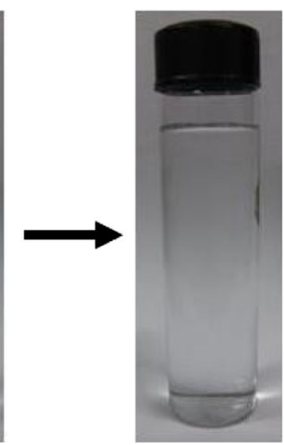

$6 \mathrm{hrs}$

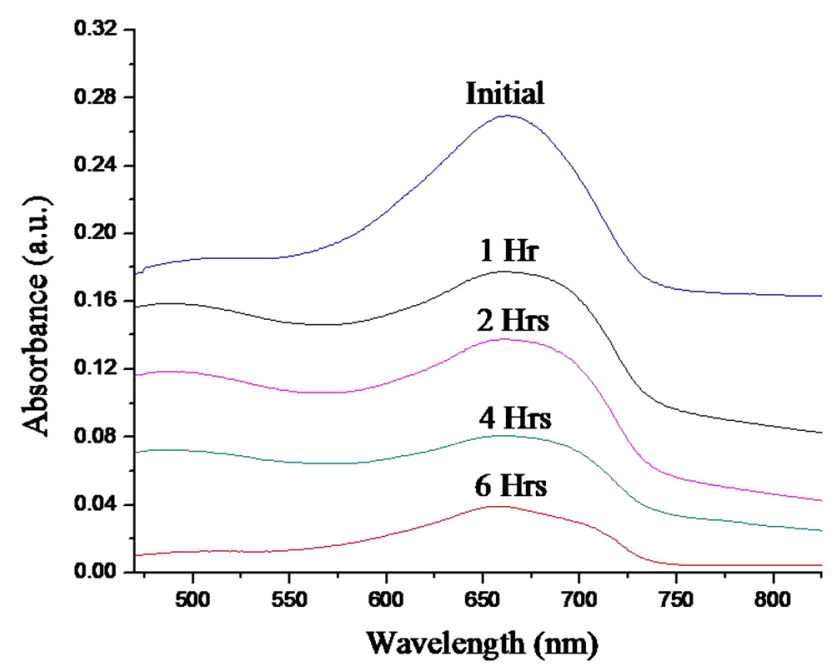

Fig. 7 UV spectra indicate photocatalytic degradation of methylene blue with reaction time

The control exhibited no change in coloration during exposure in sunlight. The dye degradation $(\%)$ was calculated using the following rule and its variance with the time of solar exposure is shown in Fig. 8.

Dye degradation $(\%)=\left[\left(C_{0}-C_{\mathrm{t}}\right) / C_{0}\right] \times 100$

Where $C_{0}$ is the initial concentration of the methylene blue solution and $C_{t}$ is the concentration of the dye solution after $t$ hours of exposure in solar irradiation. All dye concentrations were measured by taking the value of absorbance at $660 \mathrm{~nm}$ in the UV-Vis spectra as the concentration is directly proportional to the absorbance value.

The solar light was found to be more effective than other irradiation techniques for degrading dyes as reported by the previous studies (Kumar et al. 2013; Kansal et al. 2008). During exposure in sunlight, when the photons hit the nanoparticles present in the colloidal mixture, the electrons at the particle surface are excited (Yu et al. 2012). The dissolved oxygen molecules in the reacting medium accept the excited electrons from particle surface and are converted into oxygen anion radicals. These radicals break the

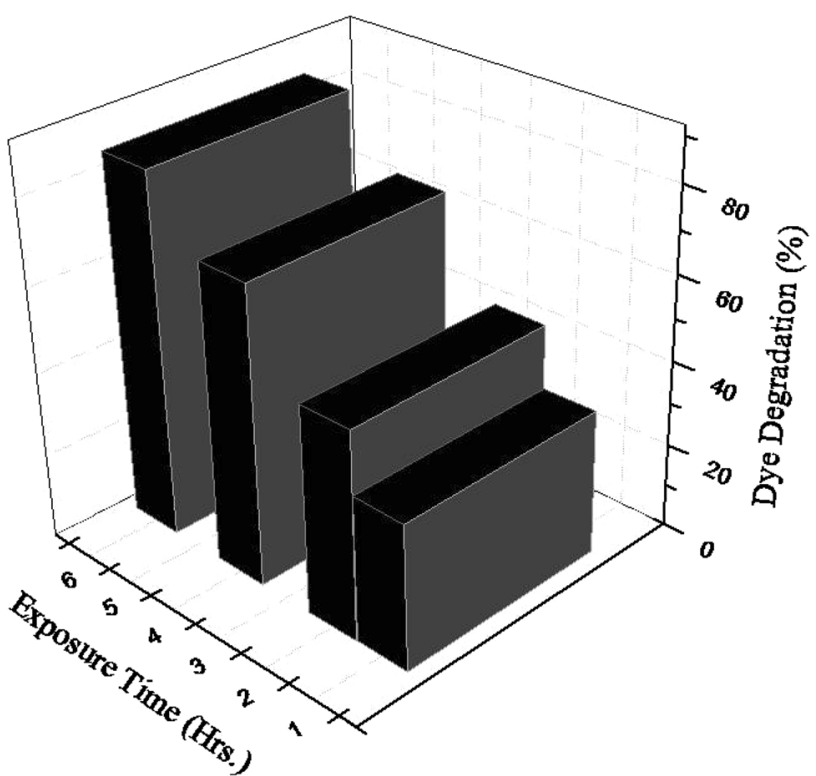

Fig. $83 D$ bar graph shows the variation of dye degradation at different exposure time

organic dye into simpler organic molecules leading to the rapid degradation of the dye (Houas et al. 2001; Ameta et al. 2013). Therefore, the biosynthesized Ag nanoparticles may act as a stable and efficient photocatalyst for degradation of methylene blue under visible light irradiation (Vanaja et al. 2014).

\section{Conclusion}

Biological synthesis of metallic nanoparticles has emerged as a simpler and better option than physical and chemical procedures as it is fast, clean and eco-friendly alternative that does not involve any costly instruments as well. Here, we synthesized silver nanoparticles from silver nitrate solution using yeast (Saccharomyces cerevisiae) extract and the biosynthesized Ag nanoparticles were found to be almost spherical in shape with an average diameter of $10 \mathrm{~nm}$. Crystalline nature of the particles was verified by 
XRD, whereas the FTIR study detected the functional biomolecules that contributed to the reduction and capping of the $\mathrm{Ag}$ nanoparticles during interaction. The result of the photocatalytic study concludes that these biogenic silver nanoparticles have efficiency to degrade methylene blue under solar irradiation. Therefore, they can find applications in textile industry and water treatment plants.

Acknowledgments One of the authors (Kaushik Roy) thanks and acknowledges CSIR for financial assistance (Senior Research Fellowship).

Open Access This article is distributed under the terms of the Creative Commons Attribution License which permits any use, distribution, and reproduction in any medium, provided the original author(s) and the source are credited.

\section{References}

Ameta A, Ameta R, Ahuja M (2013) Photocatalytic degradation of methylene blue over ferric tungstate. Sci Revs Chem Commun 3(3):172-180

Awwad AM, Salem NM, Abdeen AO (2013) Green synthesis of silver nanoparticles using carob leaf extract and its antibacterial activity. Int J Indus Chem 4(29):1-6

Banerjee P, Satapathy M, Mukhopahayay A, Das P (2014) Leaf extract mediated green synthesis of silver nanoparticles from widely available Indian plants: synthesis, characterization, antimicrobial property and toxicity analysis. Bioresour Bioprocess $1(3): 1-10$

Bastús NG, Merkoçi F, Piella J, Puntes V (2014) Synthesis of highly monodisperse citrate-stabilized silver nanoparticles of up to 200 nm: kinetic control and catalytic properties. Chem Mater 26(9):2836-2846

Bonde SR, Rathod DP, Ingle AP, Ade RB, Gade AK, Rai MK (2012) Murraya koenigii-mediated synthesis of silver nanoparticles and its activity against three human pathogenic bacteria. Nanosci Methods 1:25-36

Comparelli R, Fanizza E, Curri ML, Cozzoli PD, Mascolo G, Agostiano A (2005) UV-induced photocatalytic degradation of azo dyes by organic-capped $\mathrm{ZnO}$ nanocrystals immobilized onto substrates. Appl Catalysis B: Environ 60(1):1-11

Gomez V, Larrechi MS, Callao MP (2007) Kinetic and adsorption study of acid dye removal using activated carbon. Chemosphere 69(7):1151-1158

Honary S, Barabadi H, Gharaei-Fathabad E, Naghibi F (2013) Green synthesis of silver nanoparticles induced by the fungus Penicillium citrinum. Tropic J Pharm Res 12(1):7-11

Houas A et al (2001) Photocatalytic degradation pathway of methylene blue in water. Appl Catalysis B: Environ 31:145-157

Huang Z, Jiang X, Guo D, Gu N (2011) Controllable synthesis and biomedical applications of silver nanomaterials. J Nanosci Nanotechnol 11(11):9395-9408

Isaac RS, Sakthivel G, Murthy C (2013) Green synthesis of gold and silver nanoparticles using Averrhoa bilimbi fruit extract. J Nanotech, Article ID 906592:6 pages

Kansal SK, Singh M, Sudo D (2008) Studies on $\mathrm{TiO}_{2} / \mathrm{ZnO}$ photocatalysed degradation of lignin. J Hazard Mater 153:412-417

Kelly KL, Coronado E, Zhao LL, Schatz GC (2003) The optical properties of metal nanoparticles: the influence of size, shape and dielectric environment. J Phys Chem B 107(3):668-677
Kim YH, Hensley R (1997) Effective control of chlorination and dechlorination at wastewater treatment plants using redox potential. Water Environ Res 69(5):1008-1014

Kumar P, Govindaraju M, Senthamilselvi S, Premkumar K (2013) Photocatalytic degradation of methyl orange dye using silver nanoparticles synthesized from Ulva lactuca. Colloids Surf B: Biointerfaces 103:658-661

Lee K, El-Sayed MA (2006) Gold and silver nanoparticles in sensing and imaging: sensitivity of plasmon response to size, shape, and metal composition. J Phys Chem B 110(39):19220-19225

Li Y, Liu Q, Shen W (2011a) Morphology-dependent nanocatalysis: metal particles. Dalton Trans 40:5811-5826

Li M, Liao X, Zhang D, Du G, Chen J (2011b) Yeast extract promotes cell growth and induces production of polyvinyl alcoholdegrading enzymes. Enzyme Res, Article ID 179819:8 pages

Li G, He D, Qian Y, Guan B, Gao S, Cui Y, Yokoyama K, Wang L (2012) Fungus-mediated green synthesis of silver nanoparticles using Aspergillus terreus. Int J Mol Sci 13(1):466-476

Löberg J, Holmberg JP, Mattisson I, Arvidsson A, Ahlberg E (2013) electronic properties of $\mathrm{tio}_{2}$ nanoparticles films and the effect on Apatite-forming ability. Int J Dent, Article ID 139615:14 pages

Malarkodi C, Rajeshkumar S, Paulkumar K, Gnanajobitha G, Vanaja M, Annadurai G (2013) Bacterial synthesis of silver nanoparticles by using optimized biomass growth of Bacillus sp. Nanosci Nanotech: An Int J 3(2):26-32

Mosser et al (2011) Characterization of chromatographic yeast extract fractions promoting $\mathrm{CHO}$ cell growth. BMC Proceedings 5(Suppl 8):P99

Phanjom P, Sultana A, Sarma H, Ramchiary J, Goswami K, Baishya P (2012) Plant mediated synthesis of silver nanoparticles using Elaeagnus latifolia leaf extract. Dig J Nanomater Bios 7(3): $1117-1123$

Prakasha P, Gnanaprakasama P, Emmanuela R, Arokiyarajb S, Saravanan M (2013) Green synthesis of silver nanoparticles from leaf extract of Mimusops elengi, Linn. for enhanced antibacterial activity against multi drug resistant clinical isolates. Colloids Surf B: Biointerfaces 108:255-259

Roy K, Biswas S, Banerjee PC (2013) 'Green' synthesis of silver nanoparticles by using Grape (Vitis vinifera) fruit extract: characterization of the particles and study of antibacterial activity. Res J Pharm Biol Chem Sci 4(1):1271-1278

Sathyavathi R, Krishna MB, Rao SV, Saritha R, Rao DN (2010) Biosynthesis of silver nanoparticles using Coriandrum sativum leaf extract and their application in nonlinear optics. Adv Sci Lett 3(2):138-143

Satyavani K, Gurudeeban S, Ramanathan T, Balasubramanian T (2011) Biomedical potential of silver nanoparticles synthesized from calli cells of Citrullus colocynthis (L.) Schrad. J Nanobiotechnol 9(43):2-8

Smith BC (1999) Infrared spectral interpretation: a systematic approach. CRC Press, Florida. ISBN: 0-8493-2463-7

Sohrabi MR, Ghavami M (2008) Photocatalytic degradation of direct red 23 dye using $\mathrm{UV} / \mathrm{TiO}_{2}$ : effect of operational parameters. J Hazard Mater 153(3):1235-1239

Sudha SS, Rajamanickam K, Rengaramanujam J (2013) Microalgae mediated synthesis of silver nanoparticles and their antibacterial activity against pathogenic bacteria. Indian $J$ Exp Biol 51(5):393-399

Szpyrkowicz L (2005) Hydrodynamic effects on the performance of electro-coagulation/electro-flotation for the removal of dyes from textile wastewater. Ind Eng Chem Res 44(20):7844-7853

Tran QH, Nguyen VQ, Le A (2013) Silver nanoparticles: synthesis, properties, toxicology, applications and perspectives. Adv Nat Sci: Nanosci Nanotechnol 4:33001. doi:10.1088/2043-6262/4/3/ 033001 
Vanaja M, Paulkumar K, Baburaja M, Rajeshkumar S, Gnanajobitha G, Malarkodi C, Sivakavinesan M, Annadurai G (2014) Degradation of methylene blue using biologically synthesized silver nanoparticles. Bioinorg Chem Application, Article Id 742346: 8 pages, http://dx.doi.org/10.1155/2014/742346

Yu L, Xi J, Li M, Chan HT, Su T, Phillips DL, Chan WK (2012) The degradation mechanism of methyl orange under photo-catalysis of $\mathrm{TiO}_{2}$. Phys Chem Chem Phys 14:3589-3595
Zaniewski AM, Schriver M, Lee JG, Crommie MF, Zettl A (2013) Electronic and optical properties of metal-nanoparticle filled graphene sandwiches. Appl Phys Lett 102:23108-23116

Zhang F, Wu X, Chen Y, Lin H (2009) Application of silver nanoparticles to cotton fabric as an antibacterial textile finish. Fiber Polymer 10(4):496-501 